\title{
Villas, villagers and tortoises in Greece-a sequel
}

\author{
Adrian Hailey and Vassilis Goutner
}

\begin{abstract}
Despite protection of the species under the Berne Convention, and of the site by planning restrictions, Hermann's tortoises have again been killed at Alyki, 10 years after the original catastrophe. The authors describe the situation leading up to the recent habitat destruction, and its effect. There is a final opportunity to save the tortoise population before it is destroyed by holiday developments.
\end{abstract}

In the summer of 1980 an expedition from the University of London Natural History Society witnessed the burning and ploughing of the coastal heathland at Alyki, near Katerini in northern Greece (Stubbs et al., 1981). It was a deliberate attempt by the local community of Kitros to destroy the value of the site for wildlife (principally Hermann's tortoise Testudo hermanni, seabirds and waterfowl), and enable them to build beach chalets. It followed within months of a report on the conservation of the heath and its enclosed lagoon (Sekliziotis and Katsaounis, 1980). In this article we describe the subsequent fate of the site, culminating in a second catastrophe.

Alyki was revisited in 1982 and 1983, leading to an estimate of the 1980 disturbance (Stubbs et al., 1985); 40 per cent of the adult and subadult tortoises were killed. The heathland vegetation regenerated over this period, and the site was recovering well when surveying work was noticed in June 1983. A new road was marked out with a line of short concrete posts across the heath, and several small plots were staked out. However, after protests from the IUCN-SSC Tortoise and Freshwater Turtle Specialist Group, among others, the site was protected by a Greek Presidential Decree in 1984 (D. Stubbs and I. R. Swingland, pers. comm.). In theory this saved the site for wildlife in perpetuity, and there was no further development in the mid-1980s.

In 1989 it became apparent that the villagers were still attempting to build at Alyki (Hailey, 1989), and protests were sent to the relevant authorities. The main threat was that they would take advantage of a period of political instability in Greece. There were three general elections in the 11 months from May 1989, and the villagers acted in this absence of effective government.

\section{A second catastrophe}

There was a large fire at Alyki in November 1989, when the whole of the southern heath and most of the main heath areas (Figure 1) were burnt. The road that had been marked out in 1983 was bulldozed clear, and surfaced with gravel along the southern heath. Dozens of small plots, $20 \mathrm{~m} \times 25 \mathrm{~m}$, were marked out in a regular grid on either side of this road in the first quarter of 1990. Many of these plots were ploughed up, and two other roads were cleared along either side of the developed area. A strip $120 \mathrm{~m}$ wide was thus damaged through the centre of the heath.

The fenced plots are of the typical size for beach chalets, which are common in the Halkidiki peninsula, opposite Alyki across the Gulf of Thermaikos. These are usually illegal developments, appearing overnight like mushrooms. Those at Alyki ranged from a wooden pole at each corner, up to elaborate fences of concrete posts and barbed wire. A few were planted with maize, potatoes, olives or shade trees; most of these plants died quickly in the sandy saline soil. There was no building up to the end of June 1990. 


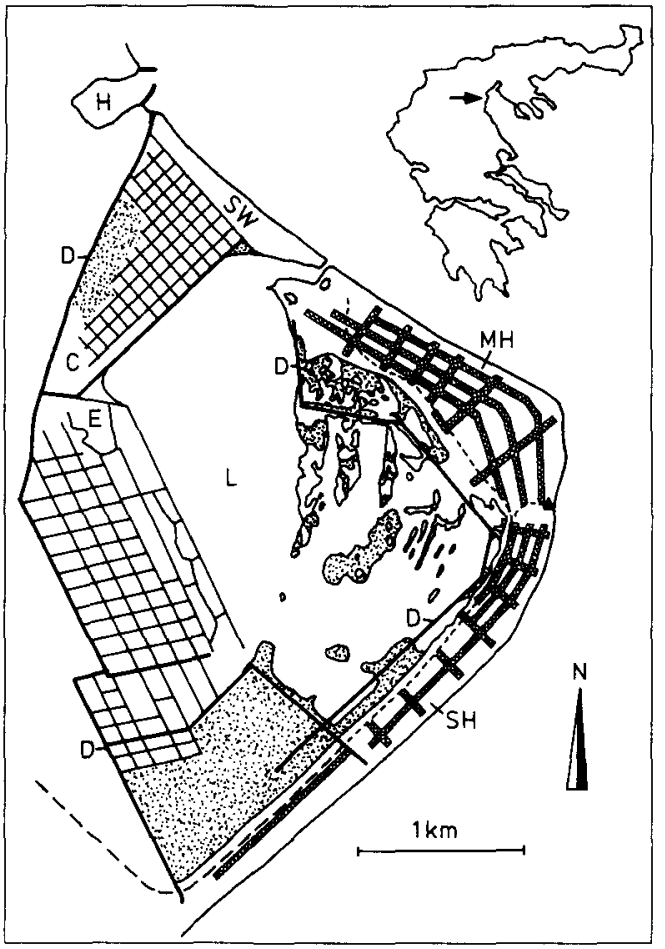

Figure 1. The Alyki site south of the harbour $(\mathrm{H})$, showing the area of destruction, 1989/1990. The lagoon (L) is enclosed by a dyke (D), and is partly developed as evaporation pools $(\mathrm{E})$ and crystallization pans (C) for the salt works (SW). The tortoise habitat is the heathland between the lagoon and the sea; the main heath (MH) north of the lighthouse (A), and the southern heath $(\mathrm{SH})$. The shaded bars are ploughed strips, between which were the building plots. Long dashes = gravelsurfaced road; short dashes = earth track; stippling = mudflats and salt marsh. Based on a map by V. Goutner, G. Papakostas and J. Tsougakis in Latsoudis et al. (1990). Inset shows location of Alyki in Greece.

The 1980 catastrophe took place at the start of the tortoise population study, when only 212 animals had been marked. Estimates of the effect on the population were therefore not precise. The second catastrophe occurred after fieldwork throughout the 1980s (Hailey, 1990); a total of 4156 tortoises were marked before 1990. Results from fieldwork in April, May and June 1990 are being analysed, but it is clear that the second catastrophe was not as damaging to the population. Over 3000 tor- toise sightings were made in these 3 months, and a further 823 individuals marked. The survival of marked adults and subadults between April 1989 and April 1990 was 83.6 per cent, compared to mean annual survival from 1982 to 1989 of 93.1 per cent. The mortality attributable to the habitat destruction was therefore about 10 per cent, a quarter that of 1980.

Two factors explain the lesser effect of the 1990 catastrophe. First, it took place between November and March, when the tortoises were hibernating. This seems to have protected them well from the fire, few animals showing new burns, but only poorly from the plough. Over 200 dead tortoises were found in the ploughed plots in the main and southern heath. Secondly, the central areas of high tortoise density had already been damaged in 1980, and had not been repopulated by 1990 . Tortoises in peripheral areas escaped both catastrophes, but made up a larger part of the total population in 1990 .

\section{Future of tortoises at Alyki}

The Alyki heath, including half of the enclosed lagoon, was given to the community of Kitros in 1932, and confirmed by a topographical survey in 1967. The heath was designated as grazing land; it cannot be altered to agriculture or building without specific authorization, and the recent habitat destruction is illegal. However, the local authority (Pierias) has not prosecuted those responsible, and has indicated that it will take no action unless building starts.

The current situation is therefore a stalemate. The villagers have again destroyed the site, and incurred the expenses of road making and fencing, but they cannot start building for fear of prosecution. The government prevents building, but takes no action against the habitat destruction. The only change is that many tortoises have again been killed, even though they have had protected status throughout the European Community since 1984.

Ecological work at Alyki continues, so that at least the effects of development can be doc- 


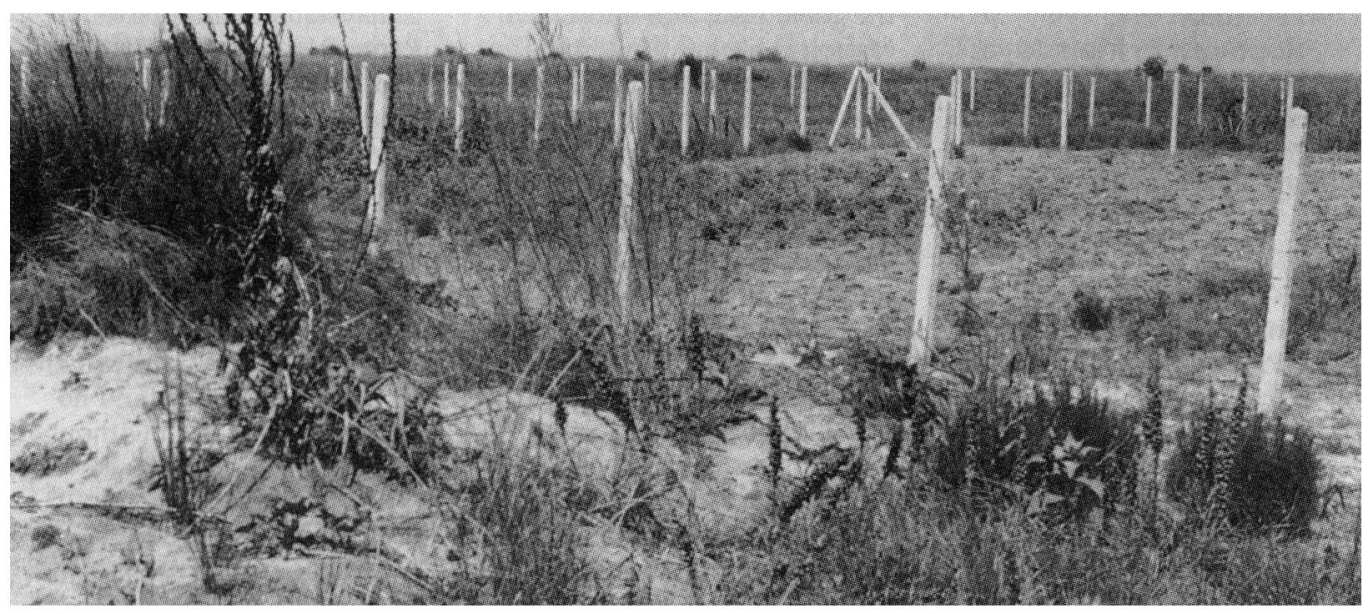

The heath at Alyki marked out for building plots (A. Hailey).

umented. In the worst case this would help to save other sites in Greece, many of which are under similar threat (Willemsen and Hailey, 1989). At best it may be possible to save Alyki by preventing the change of land use applied for recently by the community of Kitros. The site retains an important tortoise population even after the recent destruction. Alyki is also important for birds (Goutner, 1986), including a breeding colony of the Mediterranean gull Larus melanocephalus, which would be disturbed by more intensive use of the heath.

The campaign by the University of Thessaloniki and the Hellenic Ornithological Society (HOS), and organizations outside Greece, must continue. There is a hopeful precedent. A campaign by the HOS contributed to the banning of shooting at Alyki in 1987, which has proved to be effective in safeguarding the migrant waterfowl that use the lagoon in winter.

\section{Acknowledgment}

Fieldwork in 1990 was supported by a British Ecological Society grant to A. H.

\section{References}

Goutner, V. 1986. Distribution, status and conservation of the Mediterranean gull in Greece. In: Mediterranean Marine Avifauna-Population Studies and Conservation (eds B. Medmaravis and X.
Monbailliu), pp. 431-447. Springer Verlag, Berlin.

Hailey, A. 1989. New threat to Alyki tortoises. Tortoises and Turtles: IUCN-SSC Tortoise and Freshwater Turtle Specialist Group Newsletter (4), 6-7.

Hailey, A. 1990. Adult survival and recruitment and the explanation of an uneven sex ratio in a tortoise population. Can. J. Zool. 68, 547-555.

Latsoudis, P., Papakostas, G. and Tsougakis, J. 1990. The illegal development at Alyki Kitros. Report of the Hellenic Ornithological Society. Thessaloniki, March 1990 (in Greek).

Sekliziotis, S. and Katsaounis, A. 1980. Report on environmental effects of the proposed housing developments at the Lake Alyki-Pieria beach. Report to the Ministry of Co-ordination and Registrar of the National Council of Physical Planning and Environment. Athens, May 1980 (in Greek).

Stubbs, D., Hailey, A., Tyler, W. and Pulford, E. 1981. Villas, villagers and tortoises in Greece. Oryx, 16, 176-178.

Stubbs, D., Swingland, I. R., Hailey, A. and Pulford, E. 1985. The ecology of the Mediterranean tortoise Testudo hermanni in northern Greece (The effects of a catastrophe on population structure and density). Biol. Conserv. 31, 125-152.

Willemsen, R. E. and Hailey, A. 1989. Status and conservation of tortoises in Greece. Herpetol. J. 1, $315-330$

Adrian Hailey, Department of Biological Sciences, University of Zimbabwe, PO Box MP167. Mount Pleasant, Harare. Zimbabwe.

Vassilis Goutner, Department of Zoology, University of Thessaloniki, Thessaloniki TK 540 06, Greece. 